\title{
Reflections on Eriksen's seminal essay on discrimination, performance and learning without awareness
}

\author{
Randolph Blake ${ }^{1}$ \\ Published online: 15 September 2020 \\ (C) The Psychonomic Society, Inc. 2020
}

\begin{abstract}
Early in his career C.W. Eriksen published in Psychological Review what turned out to be a highly impactful critique on methods and findings on the topic of unconscious influences on discrimination and awareness. His incisive commentary on extant methodology employed at that time - especially the heavy dependence on subjective reports - clearly was heard by others moving forward, as evidenced by the subsequent, lively discussions within the literature concerning the very definition of the notion of unconscious processing. Of equal importance, Eriksen's paper provided an impetus for the development of more refined techniques for manipulating perceptual awareness and for measuring the consequences of those manipulations. My purpose in this essay is to ensure that Eriksen's seminal contributions concerning unconscious phenomena remain within the awareness of the many current investigators working on this popular topic.
\end{abstract}

Keywords Adaptation and aftereffects · Binocular vision: Rivalry/bistable perception

\section{Introduction}

Charles Eriksen's many lasting contributions being honored in this special issue rightfully include his trenchant essay titled "Discrimination and learning without awareness: A methodological survey and evaluation" (Eriksen, 1960). This essay (hereafter referred to as DLWA) deserves prominence in the unfolding - and unfinished saga of subliminal perception: the mind's propensity to be swayed by sensory information about environmental objects and events that fall outside our awareness. I am grateful for the opportunity to remind myself and other contemporary researchers about this paper and the role it has played in the evolution of our thinking about perception outside of awareness and about the challenges we face when trying to study that problem.

Randolph Blake

Randolph.blake@vanderbilt.edu; http://www.psy.vanderbilt.edu/ faculty/blake/blake.html

1 Department of Psychology/Vanderbilt Vision Research Center, Vanderbilt University, Nashville, TN 37240, USA
To start on a personal note, my appreciation of this paper dates back to my early years as a graduate student at Vanderbilt University. My mentors at that time were the late Robert Fox (one of Eriksen's close professional friends) and Joseph Lappin (one of Eriksen's accomplished graduate students). Their admiration for Eriksen's ideas were infectiously transmitted to me during my graduate training. In fact, it was Fox who introduced me to this Psychological Review paper, realizing that I was becoming infatuated with the study of binocular rivalry as a psychological scalpel for dissecting aspects of visual processing transpiring outside of awareness (Blake \& Fox, 1974). Eriksen's paper was Fox's constant reminder to me that one must maintain a healthy skepticism about subjective reports of what can be seen and what cannot, meaning that one must redouble the effort to validate "invisibility" when claiming that people do not see things that nonetheless influence their performance on behavioral tasks involving putatively "invisible" stimuli.

Based on its citation count, DLWA should qualify as a citation classic by Google Scholar standards, and the lessons taught in that paper have certainly not been lost in the mists of time. Indeed, a series of influential 
papers published over the second half of the twentieth century credit this particular paper in kindling a lively debate about perceptual processing outside of awareness (Erdelyi, 1974; Dixon 1971; Holender, 1986; Kihlstrom, 1987; Merikle \& Daneman, 1998). Those contributions, in turn, set the stage for a flood of papers published during the past 20 years on the inter-related topics of awareness and consciousness. ${ }^{1}$ The message voiced in the 1960 DLWA paper has become so ingrained in our thinking that the original citation is no longer deemed necessary. But, thankfully, this special issue gives us opportunity to revisit the essay's prescient ideas and to appreciate how its influence can be felt in contemporary research.

As a prelude, it is worth noting that this legendary figure in experimental psychology was trained in clinical psychology, with a dissertation awarded in 1950 (published the following year as Eriksen, 1951) in which Eriksen endorsed the existence of perceptual defense. ${ }^{2}$ Over that decade, however, this clinically trained psychologist increasingly embraced the mature methods and healthy skepticism of an experimental psychologist, transforming himself into a pioneer in the nascent field dubbed experimental clinical psychology. Upon assuming his first academic position at Johns Hopkins, Eriksen's interests broadened to other forms of unconscious processing including subception and learning outside of awareness. It was also while at Johns Hopkins that Eriksen partnered with his colleagues Wendall Garner and Harry Hake to create and publish their highly influential Psychological Review paper (Garner, Hake, \& Eriksen, 1956) questioning the strict operational definition of perception as discriminatory responses to given stimulus conditions (Allport, 1955). Rejecting that sterile view, Garner, Hake, and Eriksen argued that perception is a process whose properties "are induced from objectively determined relations between stimuli and responses (p. 150)," with those relations emerging from multiple, convergent operations. That paper, incidentally, justifiably can be characterized as an opening salvo in the cognitive revolution and, by extension, a harbinger of psychology's enlistment into the quest to understand the nature of consciousness (Koch, 2004; Chalmers, 1996).

\footnotetext{
${ }^{1}$ The word consciousness, according to Web of Science, appears in the titles of more than 23,000 publications during the period 2000-2020, with those publications distributed among diverse disciplines including philosophy, neuroscience, cognitive psychology, clinical neurology, and the humanities.

${ }^{2}$ Some of the biographical observations in this paragraph were harvested from the essay authored by colleagues and former students of Eriksen (Kramer et al., 1994) in honor of his retirement from the Editorship of Perception \& Psychophysics.
}

In 1956, Eriksen moved to the University of Illinois where he developed into a full-blown experimental psychologist, leaving the clinical moniker off his credentials. Still early in his career trajectory, Eriksen announced his arrival on the scene with the publication of DWLA, to which we now turn.

\section{The central message in DLWA}

Eriksen introduces his essay by questioning the usefulness of the notion of consciousness as it was being used in the literature of his day. In so doing, Eriksen was foreshadowing what others have since echoed about the vagueness of that term, including philosopher Ned Block (1995), who has colorfully characterized consciousness as a "mongrel concept." In DLWA, Eriksen instead opined that his aim was to focus on discrimination and awareness, an approach more amenable to the rigor of convergent operational definition (Garner et al., 1956). At the risk of putting words in Eriksen's mouth, my impression is that his conceptualization of awareness included the appearance of things ("content consciousness" as philosophers would call it) as well as the implications of what that appearance conveyed about the opportunities afforded by things we're looking at. But there's no getting around the limitation that the contents of awareness are inherently subjective (Koenderink, 2012). Dissenting opinions are welcome.

To set the stage for the lessons appearing in DLWA, let's begin by considering what Eriksen wrote in the concluding section of his essay:

"...at present there is no convincing evidence that the human organism can discriminate or differentially respond to external stimuli that are at an intensity level too low to elicit a discriminated verbal response.... There is a great need to spell out explicitly the assumed characteristics of the unconscious and to search for explanations of so called unconscious phenomena in terms of more common-place psychological variables.” p. 298

In reaching this conclusion, Eriksen critiqued several methodological strategies that had been used to assess subliminal discrimination (i.e., dissociations between verbal report and other measures of the impact of weak sensory stimulation). The following subsections summarize those strategies and Eriksen's reservations about them. In those subsections, I also give selective examples of more recent work that arguably sidesteps some of those reservations and, thus, allows more refined tests for the existence of discrimination outside of awareness (see Text Box 1). 


\section{Text Box 1: The Eriksen Challenge}

For a historical account of subsequent pushback to $D L W A$ and revival of subliminal perception as a matter of scientific relevance, the chapter written by Kihlstrom (1996) is well worth reading, particularly the section titled "The Eriksen Challenge." As a teaser, here is what Kihlstrom wrote about $D L W A$ :

"Certainly the most powerful and influential criticism of subliminal perception came from C.W. Eriksen.... Perhaps reflecting the influence of functional behaviorism, Eriksen was extremely critical of any definition of awareness in terms of verbal reports or confidence ratings, and he was equally critical of the methods used to determine thresholds in subliminal perception experiments.... he evidently distrusted verbal reports as indices of conscious experience, and instead preferred discriminative behavior for this purpose. This created a paradox .... because above-chance discriminative responses are the means by which perception without awareness is documented in the first place. If conscious perceptual experience is to be inferred from any discriminative response, this would seem to mean that subliminal perception is ruled out by fiat." (p. 25).

Indirect, physiological measures As described by Eriksen, this strategy involves using an involuntary physiological response such as the galvanic skin response (GSR) or the pupillary reflex together with verbal report to ask if those two response modes - autonomic and behavioral - can be dissociated. The two versions of this strategy were to use classical conditioning to determine whether: (1) a conditioned, autonomic reflex could be established using subthreshold stimulation (Wilcott, 1953), or (2) whether a previously conditioned autonomic reflex established using a suprathreshold conditioned stimulus could then be evoked by subthreshold intensity levels of the conditioned stimulation (e.g., Newhall \& Sears, 1933). With the latter version of this strategy, it was further possible to ascertain whether an autonomic response still occurred on trials when the behavioral response was incorrect, in effect generating a pair of psychometric measures obtained concurrently (Lazarus \& McCleary, 1951). Without going into specific reasons, suffice it to say that Eriksen was generally skeptical of the implementation of these strategies and the oversimplified analyses of the partial correlations of data comprising those two response categories. Eriksen was unconvinced that indirect, autonomic responses are more sensitive at discriminating stimulus presentations than are verbal responses, in part because he was skeptical about the validity of verbal responses.

The approach highlighted in the previous paragraph relied on classical conditioning to empower mundane visual stimuli (e.g., flashes of light) with the capability to evoke autonomic reactions such as GSR. But not all stimuli require preconditioning - some are inherently arousing (e.g., a straight flush hand in poker) as evidenced by the autonomic responses they provoke (e.g., brisk pupillary dilation, as savy poker players recognize). ${ }^{3}$ Moreover, in the laboratory the visibility of such stimuli can be removed from awareness by any one of several psychophysical tricks, as summarized in a subsequent section, that can be deployed to address this question: Does a normally visible, affectively charged image still evoke reflexive autonomic responses when suppressed from awareness? During recent years contemporary work has attempted to answer that question. Thus, for example, there is evidence that an emotionally charged visual stimulus viewed by one eye (e.g., a picture of a spider) tends to dominate in binocular rivalry when pitted against a neutral stimulus viewed by the other eye (Sheth \& Pham 2008; Gerdes \& Alpers, 2014). In a similar vein, images of angry faces initially suppressed from awareness during rivalry emerge into dominance more quickly than do neutral or happy faces, an effect that may be traced to the salience of the widened eyes accompanying threatening facial expressions (Gray et al., 2010; Whalen et al., 2004; Yang et al., 2007). And pictures of nude human bodies continue to serve as effective cues guiding spatial attention even when they are suppressed from awareness by the potent form of interocular masking called continuous flash suppression (CFS), (Jiang et al., 2006). Tamietto and de Gelder B (2010) and Hedger et al. (2016) provide good reviews of this controversial literature on affective processing outside of awareness.

Dual-report strategy Another methodological approach critiqued by Eriksen in DLWA is the dual-report procedure wherein each detection trial entails collecting a participant's trial-by-trial report about detectability of a stimulus together with a numerical confidence rating about the correctness of the participant's judgment on each trial. Detection tasks typically required a yes/no answer or a forced-choice response about some characteristic of the stimulus (e.g., in which one of two intervals was it presented). Eriksen was aware that in a number of studies (e.g., Adams, 1957) the dual report method revealed that participants can perform above chance under conditions where they indicate having zero confidence in their judgment on a significant number of trials. For Eriksen, this

\footnotetext{
${ }^{3}$ One could write an article on the fascinating studies that have been published recently on the pupillary reflex and its sensitivity to non-photic, psychological factors, some of which exert their influence outside of consciousness (see, e.g., Binda et al., 2013; Jagiello et al., 2019; Naber \& Nakayama, 2013; Laeng \& Sulutvedt, 2014; Schwiedrzik \& Sudmann, 2020).
} 
pattern of results further undermined the utility of verbal report for building a science of awareness. Eriksen also expressed skepticism about the validity of scaling based on verbal descriptors as operational definitions of awareness (e.g., see the Perceptual Awareness Scale devised by Ramsøy and Overgaard, 2004) because rating scales were difficult to standardize across experiments or to normalize across participants. Rating scales, in his opinion, were a starting point but, nonetheless, do not uniquely constitute the "operational specification" needed to nail down awareness.

In the contemporary literature on awareness we find multiple instances where versions of the dual-report procedure have been utilized (see, e.g., the paper titled "Blindsight in normal observers" by Kolb \& Braun, 1995, and the rejoinders to this paper by Morgan et al., 1997 and by Robichaud \& Stelmach, 2003). Moreover, there have been important advances in quantifying the relation between sensory discrimination and judgment confidence that, in my opinion, go some way toward redressing the concerns voiced by Eriksen. I would particularly urge readers to read the theoretical paper by Galvin et al. (2003) in which the authors derive an operational definition of perception without awareness within the context of statistical decision theory. Their formulation is based on the distinction between Type 1 judgments ("which one of $n$ possible events is most likely to have happened on a given trial") and Type 2 judgments ("what is the likelihood that my Type 1 judgment was correct on that trial"). Galvin et al. develop a strong case for the conclusion that evidence implicating perception without awareness can be derived by comparing the prediction of Type 2 performance based on Type 1 performance. Without going into details of that derivation, their theory posits that if participants can discriminate between signal and noise but cannot discriminate between their own incorrect and correct decisions, this constitutes evidence for perception without awareness.

To be sure, the debate about the validity of dual-report procedures for dissociating awareness (e.g., confidence rating, wagering) from perceptual performance has endured in the literature and remains a topic of controversy (see, e.g., Dienes and Seth, 2010; Overgaard et al., 2010; Soto et al., 2011).

Subsequent impact of subliminal stimulation The last class of methods critiqued in DLWA are ones that entail two successive phases: (1) a presentation period during which a complex, meaningful stimulus is viewed under conditions that temporarily disrupt perceptual awareness of that stimulus, and (2) a subsequent behavioral assay of the residual effectiveness of that lack of awareness. To what extent, in other words, does a stimulus retain its effectiveness when a person is unaware of its presence?

During the period of time that Eriksen was working, studies tended to rely on reductions in the intensity, contrast, or exposure duration of stimuli to render them perceptually invisible. To exemplify this strategy, $D L W A$ refers to a study (Dixon, 1958) in which participants were shown a series of 12 different words, some neutral (e.g., "barn") and others with emotional connotation (e.g., "penis"), and each word was presented at a luminance and exposure duration rendering the words unidentifiable. After each presentation, which was signaled by a visible spot of light, participants were forced to guess what the word was, based on the first thought that came to mind. During this phase of the experiment, participants received four repetitions of this series of subliminal exposures of the 12 words, and on no trials were their guesses the correct answer. A week later participants returned to the lab and were given a randomly ordered list of the subliminally presented words, all of which they reported as being unfamiliar. They were then read, one at a time, a word drawn from the list of the participant's own responses during the previous, subliminal presentation phase and told to pick from the list of words they held the one most likely to match a particular response based on any associative connection that came to mind. Data pooled over participants revealed that the incidence of "correctly" pairing a subliminal word with the response guess made a week before to that word was significantly greater than that predicted based on chance, leading Dixon to conclude that subliminal words could be unconsciously perceived. Moreover, Dixon recorded GSRs during the subliminal phase of the experiment, and those measures revealed that the emotionally valenced, unseen words evoked stronger autonomic reactions than did neutral words.

In a replication and extension of Dixon's behavioral study (Fuhrer \& Eriksen, 1960), Eriksen confirmed the behavioral result but also included control conditions (e.g., brief exposure of inverted words) showing that it was structural, not semantic, aspects of the subliminal words (e.g., number of letters) that were likely deployed when participants formulated their "guesses" about word associations. Eriksen nonetheless acknowledged that "there are most likely circumstances where a nonverbal response may be a better indicator than verbalization" (p. 291) when it comes to assaying the residual effectiveness of a stimulus that escapes one's awareness. The following section summarizes Eriksen's prescient thoughts on that possibility, and it highlights some of the ways in which those circumstances have been created in contemporary work. 
Learning without awareness Eriksen highlighted another class of studies that he lumped under the rubric "discrimination without awareness." The gist of these phenomena is a participant's acquisition over trials of knowledge about some seemingly irrelevant, non-obvious property of visual stimuli that are the focus of a task unrelated to that property. Examples of this kind of unintentional learning can be drawn from the contemporary literature showing that people unwittingly acquire information about statistical regularities in arrays of complex figures as evidenced by their performance on tasks involving visual search (Chun \& Jiang, 1998) and shape familiarity (Fiser \& Aslin, 2001). This kind of acquired knowledge about stimulus contingencies has also been demonstrated under conditions where a critical aspect of visual stimulation supporting successful associative learning was blocked from awareness by a camouflage maneuver (Di Luca et al., 2010). These findings on incidental perceptual learning fit neatly into conceptualizations of perception that emphasize the importance of learning statistical regularities about our world, especially in situations where vital visual information is missing or is ambiguous (Purves \& Lotto, 2003; Geisler, 2008).

\section{Notable developments following publication of DLWA}

By the second half of the DLWA essay, we readily understand that Eriksen reserves the term "subliminal" for situations where a stimulus is degraded in visibility to a point where it cannot be detected or identified. And for him, studies with appropriate control conditions find no demonstrable impact of subliminal stimuli on discrimination. At the same time, he acknowledges the likelihood that ordinarily visible, supraliminal stimuli can and often do retain their effectiveness in shaping perception even when those stimuli fall outside of one's awareness. These conclusions are summed up in this quote:

"While we have been unable to find evidence for a supersensitive discriminating unconscious, the evidence that behavior can be directed by above threshold cues of which the $\mathrm{S}$ is unaware is not only more plausible but somewhat more substantial. Common sense tells us that we are constantly utilizing cues of which we are unaware in our perception of depth, of shape and size constancy..." p. 293, DLWA.

See Text Box 2 for some additional thoughts on "essential cues" that operate outside of awareness.

In the years following publication of $D L W A$, new strategies have been developed and refined that permit manipulation of visual awareness and, thus, evaluation of the extent to which an ordinarily visible object or event retains some degree of effectiveness to influence our reactions to those objects or events. The next subsection highlights several of the most popular tactics and illustrates ways in which those tactics have been deployed.

\section{Text Box 2: Eye of Origin: My Brain Knows But My Mind Doesn’t}

Eriksen's acknowledgement that perception is shaped by essential cues operating outside of our awareness is, in fact, an ancient idea introduced ten centuries ago by the Islamic genius Al-Hazen (1024/1989) and popularized in the $19^{\text {th }}$ century by two of the leading European scientific figures, Charles Wheatstone (1838) and Herrmann von Helmholtz (1867). In the current century, this notion has been popularly framed within the context of Bayesian inference (Knill \& Pouget, 2004). As a binocular vision aficionado, one of my favorite examples of a perceptually essential source of information that viewers are unaware of is eye-of-origin information.

Psychophysical evidence confirms that people with normal binocular vision are woefully bad at discerning which one of the two eyes has received monocular stimulation (Blake \& Cormack, 1979; Baker, 2017). And when they do manage to get the right answer, they often report basing their success on a 'feeling of strain' in the stimulated eye and not on visual awareness per se. In a similar vein, when viewing dissimilar monocular images simultaneously in a stereoscope, you will see one image and then the other successively over time with periods of mixture (binocular rivalry) but it's not at all obvious which eye is seeing which image. Despite this inability to specify which eye is looking at what, people can correctly judge the relative depth ordering among objects in a 3D stereogram (Shimojo \& Nakayama, 1990) and can accurately describe subtle 3D surface curvature portrayed by randomly textured stereo-images (Norman et al., 1991), based on optical/geometric constraints that dictate which eye should be seeing which image. Those remarkable feats are possible only if the brain knows which retinal image is arising from which eye. Eye-of-origin information, in other words, must be automatically and unconsciously registered by the brain and used to derive 3D visual structure and depth relations. 


\begin{tabular}{|c|c|c|c|c|c|c|c|c|}
\hline \multirow{2}{*}{$\begin{array}{c}\text { Overarching } \\
\text { themes }\end{array}$} & \multicolumn{4}{|c|}{ Stimulus generality } & \multicolumn{4}{|c|}{ Effectiveness } \\
\hline & $\begin{array}{l}\text { Variety of } \\
\text { stimuli a }\end{array}$ & $\begin{array}{l}\text { Stimulus } \\
\text { size }\end{array}$ & $\begin{array}{l}\text { Visual field } \\
\text { bocation o }\end{array}$ & $\begin{array}{l}\text { Temporal aspects } \\
\text { of stimulation d }\end{array}$ & $\begin{array}{l}\text { Unambiguous } \\
\text { invisibility }\end{array}$ & $\begin{array}{l}\text { Invariant } \\
\text { stimulation }\end{array}$ & Duration: & Predictability ${ }^{n}$ \\
\hline \multicolumn{9}{|l|}{ Backward masking } \\
\hline Crowding & ? & ? & & & & & & \\
\hline \multicolumn{9}{|l|}{ Bistable figures } \\
\hline \multicolumn{9}{|l|}{ Binooular nivalry } \\
\hline \multicolumn{9}{|l|}{$\begin{array}{l}\text { Motion-induced } \\
\text { bindness }\end{array}$} \\
\hline \multicolumn{9}{|l|}{$\begin{array}{l}\text { Inattentional/ } \\
\text { Change blindness }\end{array}$} \\
\hline Attentional blink & & & & & & & & \\
\hline \multicolumn{9}{|c|}{ Relative strength } \\
\hline \multicolumn{9}{|c|}{ Weak } \\
\hline & & & & & & & & Scien \\
\hline
\end{tabular}

Fig. 1 Strategies for evaluating effectiveness of visual stimulation presented outside of awareness. Chart reproduced with permission from Kim and Blake (2005) listing and critiquing various visual phenomena where visual awareness of a normally visible stimulus is impaired or abolished. Each phenomenon is given an ordinal "grade" ( weak to strong) on qualities divided into two categories: stimulus generality (i.e., range of conditions within which the phenomenon occurs) and effectiveness (i.e., does the state of unawareness produced by the

Contemporary strategies for rendering the visible "invisible" Some years ago Chai-Youn Kim and I published an essay evaluating a variety of popular psychophysical phenomena characterized by induced fluctuations in visual awareness (Kim \& Blake, 2005). ${ }^{4}$ Among the phenomena evaluated were visual masking (e.g., Kouider \& Dehaene, 2007), visual crowding (e.g., Levi, 2008), attentional blink (e.g., Dux \& Marois, 2009), bistable figures (e.g., Sterzer et al., 2009), and binocular rivalry (e.g., Blake \& Logothetis, 2002). Figure 1 reproduces the Table summarizing our interpretation of the strengths and weaknesses of each of these phenomena as tools for studying perception outside of awareness. Our essay concluded that the most compelling and effective phenomena were those characterized by robust fluctuations in perception relatively unconstrained by exposure duration, retinal location, or stimulus complexity. For assaying visual processing outside of awareness, we further singled out phenomena evoked by unchanging physical stimulation: in other words, what you are looking at remains the same but what you are seeing changes over time (i.e., phenomena exhibiting multistability).

Two prominent phenomena - bistable figures and binocular rivalry - satisfy that criterion, but the two differ in two important respects: (1) when viewing bistable figures (e.g., vase/face figure), the inducing stimulus and its constituent features do not phenomenon involve complete, unambiguous, invisibility of the stimulus?). Not included in this chart is continuous flash suppression (CFS, described in the text) because it had not yet been discovered. Based on the grading scheme above, CFS would receive ratings of strong for all eight qualities. (Reprinted from Trends in Cognitive Sciences, 9 (8), C.Y. Kim, R. Blake, Psychophysical magic: rendering the visible "invisible." 2005, with permission from Elsevier)

disappear and, instead, it's your interpretation of what you're seeing that changes unpredictably; (2) during binocular rivalry, however, one of two dichoptically viewed, dissimilar stimuli, constituent features included, can be erased from awareness for several seconds at a time while the other stimulus is perceptually dominant. With bistable figures, in other words, the inducing figure persists in your awareness but you're confused about what it portrays; with binocular rivalry the two dissimilar inducing figures themselves replace one another in awareness over time. But in both instances, the brain is confused, figuratively speaking, about what object the eyes are looking at, and the brain resolves this confusion by entertaining each possibility alternately over time. It also appears that volitional control over what you see is easier to achieve when viewing bistable figures than it is when experiencing binocular rivalry (Meng \& Tong, 2004), a relevant consideration when deciding which psychophysical "trick" to deploy for a given purpose. For more on binocular rivalry from one person's perspective, see Text Box 3 .

Based on the number of citations to studies employing binocular rivalry during the years spanning 1960-2010, rivalry qualified as the favorite procedure for inducing fluctuations in visual awareness, edging out visual masking (Fig. 1 in Hedger et al., 2016). But in 2005 (Fang \& He, 2005; Tsuchiya \& Koch, 2005) rivalry was displaced in popularity 


\section{Text Box 3: One Person's Lessons Learned from Studying Binocular Rivalry}

For years a number of labs, mine included, have devoted considerable effort evaluating the extent to which stimuli viewed under conditions of binocular rivalry retain at least some of their effectiveness while suppressed from awareness (Blake, 1998), where 'effectiveness' is gauged by the concurrent impact on other aspects of visual perception including grouping (e.g., Alais \& Blake, 2015), cue-directed attention (e.g., Schall et al., 1993), pattern or motion adaptation (e.g., Blake et al., 2006), interpretation of illusions (e.g., Sobel \& Blake, 2003), or by a suppressed pattern's subsequent impact on aspects of cognition (e.g., Cave et al., 1998). To be sure, the literature on the topics mentioned above is much larger than just those papers, and controversies remain to be resolved (Blake, 2014). Still, it can be said with some confidence (and without offending others) that low-level stimulus content such as contour orientation and direction of visual motion can survive suppression so long as the features conveying that information are sufficiently strong in the first place. Higher-level object representations such as faces and words, however, are more vulnerable to suppression of awareness during rivalry (e.g., Alais, 2012). But - and this is important to keep in mind - the predominance of a given stimulus engaged in binocular rivalry (i.e., the percentage of time it dominates during an extended bout of rivalry) can be significantly boosted solely by its familiarity, its congruence with concomitant motor activity, its semantic relation within a larger scene, or with sensory events arising within other modalities. These kinds of top-down influences on predominance are not surprising: during dominance phases of rivalry, the dominant stimulus engages all of the complex processing engaged during ordinary, non-rivalry viewing. The relative strength of a rival stimulus, in other words, can be endowed by low-level variables such as contrast as well as by high-level factors such as predictability, affective connotation, familiarity, focused attention and all the other 'high-level' influences that are deemed to impact what we see.

by introduction of a new, remarkably robust phenomenon called continuous flash suppression (CFS). A form of interocular suppression, this technique entails presenting to one eye a montage of different patterns one after the other at a steady, brisk rate while the other eye views a stationary pattern. A variety of CFS montages have been successfully deployed, including Mondrian-like arrays of different sized, colored rectangles (Tsuchiya \& Koch, 2005), arrays of small geometric figures (Fang \& He, 2005), extended series of natural scene images (Kim et al., 2017), and arrays of pointillist like pictures (Cha et al., 2019). These dynamic animations using densely contoured figures can effectively suppress a monocular stimulus presented to the other eye, with durations of suppression lasting considerably longer than ordinary suppression durations associated with conventional rival displays while, at the same time, minimizing the incidence of mixed dominance states that can corrupt states of dominance during binocular rivalry (Blake et al., 2019). ${ }^{5}$ Not surprisingly, CFS was eagerly adopted for studies of visual processing outside of awareness (see reviews by Gayet, Van der Stigchel, \& Paffen, 2014; Hedger et al., 2016; Prioli \& Kahan, 2015; Sterzer, Stein, Ludwig, Rothkirch, \& Hesselmann, 2014; Yang, Brascamp, Kang, \& Blake, 2014). And more recently, CFS has been utilized to tackle a diverse set of questions ranging from the ability to process multiple-word verbal expressions and solve arithmetic equations outside of awareness (Sklar et al., 2012) to identifying perceptual concomitants of developmental disorders such as autism (Madipakkam et al., 2017) and schizophrenia (Seymour et al., 2016).

Neurological conditions affecting awareness Eriksen's 1960 Psychological Review article made no mention of neuropsychological results that potentially bear on the question of perception without awareness, a rich literature dating back to the late nineteenth century (LeDoux et al., 2020). In his defense, Eriksen did not concern himself with the neural concomitants 
of visual awareness, so he cannot be faulted for this omission. Still, Eriksen's strong opinions voiced in DLWA about methodological flaws in extant studies of discrimination without awareness surely would have aroused his interest in the emerging work on blindsight, a syndrome that burst on the scene just over a decade after DLWA was published (Weiskrantz et al., 1974). This notable clinical condition was characterized by accurate visually guided behavior achieved in the absence of visual awareness of the object guiding the response (Cowey \& Stoerig, 1991; Stoerig et al., 2002; Weiskrantz, 1980), and in later studies blindsight has been extended to unconscious registration of other visual dimensions ranging from color (Cowey \& Stoerig, 2001) to facial expressions (de Gelder et al., 1999). The lack of awareness defining this syndrome is attributable to visual field defects caused by geniculo-cortical brain damage, and for that reason blindsight has provided grist for the mill among those who quarrel about the necessity of primary visual cortex for conscious visual experience (e.g., Barbur et al., 1993; Silvanto \& Rees, 2011; Tong, 2003). Originally derived to characterize a clinical condition associated with hemianopia, the term "blindsight" has now crept into the lexicon of papers describing healthy individuals whose performance is relatively unimpaired on tasks where normally visible objects retain their effectiveness despite being erased from awareness by transcranial magnetic stimulation (Boyer et al., 2005; Christensen et al., 2008), by visual camouflage (Kolb \& Braun, 1995), by metacontrast masking (Lau \& Passingham, 2006), or by CFS (Vieira et al., 2017).

In a related vein, studies of patients with damage to restricted areas within the occipital, the parietal, or the temporal lobes can exhibit patterns of selective visual deficits that suggest dissociation of awareness of different qualitative aspects of object perception. This literature has spawned impactful ideas about visual specialization within multiple areas identified within dorsal and ventral cortical streams (de Han \& Cowey, 2011; Goodale \& Milner, 1992; Kravitz et al., 2011; Mishkin et al., 1983). Pertinent to the topic of this essay, patients have been described who are unable to perform normal visual discriminations based on certain object properties such as object shape (i.e., they exhibit "shape blindness") but are reasonably accurate at reaching and appropriately grasping those objects with a facility that belies their shape blindness. This line of research has been generalized to normal individuals tested behaviorally under conditions that putatively isolate functions identified with those different visual streams (e.g., Breitmeyer, 2014; Ludwig et al., 2015), and in brain imaging studies where activations within select visual areas of the human brain can be correlated with the degree of awareness of given visual qualities of objects (e.g., Fang \& He, 2005; Tettamanti et al., 2017; Tong et al., 1998).

Perceptual awareness evoked by intrinsically arising neural activity Eriksen's essay did not dwell on neural concomitants of awareness other than to point to physiological measures (e.g., GSR) as proxies for awareness. But he did delineate what was called the concurrent response model (Eriksen, 1956) to account for partial correlations between physiological measures and verbal reports. How might that be related to contemporary work? I think they might be related, so bear with me as we work through the following line of reasoning.

These days we take it as a given that the necessary ingredients for the emergence of perceptual awareness are distinctive patterns of neural activity. The question of what constitutes those unique activity patterns remains an ongoing debate (Brascamp et al., 2018), and Maier and Tsychiya's essay in this special issue provides an updated account of this debate. Whatever those brain states supporting awareness may be, they are arising within a larger sea of neural activity that fluctuates intrinsically (i.e., even in the resting state the brain is not inactive). It is not unreasonable to assume that those fluctuations may at times - in the absence of external sensory input achieve levels and patterns sufficient to provoke a state of awareness that is indistinguishable from the state associated with genuine, externally triggered awareness. Willfully generated eidetic images could be construed as an example of these kinds of intrinsically generated states of awareness, as could unbidden hallucinations. Indeed, brain imaging studies confirm that both visual imagery (Pearson \& Kosslyn, 2015) and auditory hallucinations (Diederen et al., 2012) can be accompanied by activation patterns distributed within modalityspecific sensory brain areas.

The same broad conclusion has been advanced by some investigators as an explanation of chromatic synesthesia, the vivid visual experience that achromatic test figures, typically alphanumeric characters, appear distinctly colored (see reviews by Kim \& Blake, 2013; Ward, 2013). In this unusual but non-pathological condition, one component of a person's perceptual awareness (e.g., the form of the letter A) is readily traceable to an external stimulus while a concomitant, obligatory sensory quality of that stimulus (e.g., the letter's redness: A) arises from intrinsic neural events unrelated to specific wavelengths of light received by the eyes. In some studies, but certainly not all, synesthetic experience is accompanied by concomitant, intrinsically arising neural activity within sensory brain areas, including the putative color areas within the ventral stream network (e.g., Hubbard et al., 2005). As an aside, people who possess synesthesia often go years before realizing to their great surprise that their extra-colorful visual world is highly exceptional and not the norm - they are unaware that their color awareness is illusory.

Finally, consider the following scenario and what it implies about intrinsically generated visual awareness. Those of us who have spent time in a dark, quiet test room attempting to detect faint sounds or near-threshold visual events have learned that on occasional trials stimulus awareness can be evoked even when no external stimulus has been presented. 
When testing is structured in the form of a yes/no detection experiment, these mistaken judgments are dubbed "false alarms" and are chalked up to the confluence of internal noise and a liberal criterion for saying "yes, I detected it." The judgment is deemed objectively incorrect, because the experimenter knows for certain that no stimulus was actually presented. But from the standpoint of awareness, false alarms can provide grist for the mill, so to speak. Consider, for example, the study performed by Ress and Heeger (2003). They used fMRI to monitor BOLD signals associated with neural activity arising within a person's visual cortex while, at the same time, that person was making present/absent judgments about the brief presentation of faint, low-contrast spatial patterns presented on some, but not all, trials on a video screen being viewed by the person while lying inside the scanner. By design, this behavioral signal-detection task generated hits, misses, correct rejections, and false alarms, allowing Ress and Heeger to analyze separately the BOLD signals associated with those various categories of responses. As expected, the BOLD signal was significantly larger in amplitude (i.e., neural responses were stronger) on trials when the person reported detection of the actual presentation of a low-contrast pattern compared to the BOLD signal measured on trials when the person responded "no" in the presence of that same weak stimulus. The remarkable finding, however, was that the BOLD response on false-alarm trials - i.e., when the stimulus was not presented but the person said "present" - was significantly larger than the BOLD signal measured when the stimulus was presented but reported as "absent" by the participant. In a real sense, this finding corroborates a central tenet of SDT: owing to fluctuations in neural noise, we can occasionally perceive things that are not really there!

Variations in awareness of visual appearance The focus in $D L W A$ was on situations where awareness was abolished from consciousness, for example, a designated visual "target" cannot be seen. But as we know, the vision literature is chock-full of instances where the appearance of an object (or an event), while not blocked from awareness, is nonetheless conspicuously altered as a consequence of (1) the context in which that object appears, (2) our expectations about what we're looking at, and (3) our prior experience including exposure to other objects or events. These alterations in appearance can pertain to low-level visual features such as contour orientation (Gibson \& Radnor, 1937), surface color (Purves \& Lotto, 2000), contour width (Blakemore \& Sutton, 1969), or direction of visual motion (Wohlgemuth, 1911), as well as to highlevel interpretations of appearance such as perceived facial expression (Thompson, 1980), apparent size (Kaufman \& Kaufman, 2000), or visual event perception (Sekuler et al., 1997). This should serve as a reminder that the term "awareness" can have multiple meanings and that we need to be mindful of what aspects of awareness we are focusing on when considering perception outside of awareness. I was vividly reminded of this distinction upon seeing that a colored visual pattern subjected to CFS was fractionated into distinct features: the spatial configuration of the pattern could not be discerned under forced-choice testing but its color could be accurately reported (Hong \& Blake, 2009). Color information survived CFS but form information did not. In a subsequent study a few years later, colleagues and I observed another instance of fractionation by CFS, this one involving form and flicker (Zadbood et al., 2011; see also Carlson \& He, 2000 , for an example of form/flicker fractionation in the case of binocular rivalry). CFS, in other words, has the intriguing ability to disrupt unitary awareness of seemingly integrated features (Moors et al. 2017).

This is an appropriate place to acknowledge that "awareness" may not always be an all-or-none mental state but, instead, may at times be graded in terms of qualitative clarity (e.g., Dubois \& Faivre, 2014; Lau \& Passingham, 2006). As mentioned earlier, efforts have been made to construct scales (Ramsøy, et al., 2004; Zeki \& Ffytche, 1998) and standardized inventories (Niikawa, Nishida \& Miyahara, in press) that capture the graded quality of awareness. Moreover, awareness - like attention and visual working memory - has a given channel capacity that can be uniquely quantified by deriving the rate of change in the survival function of yet to be detected items within arrays differing in the number of items (Lappin et al., 2016). Lappin et al. (2020) speculate that this property of awareness may contribute to wellknown failures of perceptual awareness documented in the laboratory (e.g., Simons \& Chabris, 1999) as well as in important real-life situations (Drew et al., 2013).

\section{Conclusion}

To wrap up this essay succinctly, Charles Eriksen was an influential force in the emergence of our thinking about discrimination and learning outside of awareness, both in terms of his healthy skepticism about the literature on that topic during his nascent career and in terms of his subsequent contributions to the literature on attention and the flanker effect, as documented in other essays in this special issue. It can be said with confidence that the impetus for the recently developed techniques and more sophisticated analytic techniques for exploring visual processing outside of awareness were propelled by the skepticism voiced by $D L W A$ as well as the avowed confidence of $D L W A$ in the rigor of psychophysics to overcome skepticism about the potency of unconscious processes in shaping perception: visually important objects and events can indeed be processed in psychologically meaningful ways even though they have not been consciously identified. Eriksen's skeptical prodding was an essential impetus in guiding us to a confirmation of that intuition. Indeed, the message contained in DLWA is in the DNA of contemporary thinking 
about awareness and its neural concomitants. In that respect Eriksen satisfied the aim he expressed in the concluding sentence of this classic paper:

"..to search for explanations of so called unconscious phenomena in terms of more common-place psychological variables. To do so may destroy the titillating mystery that the unconscious seems to hold, but then that is the business of science." p. 298

Acknowledgements This essay is dedicated to the memory of the late Robert Fox, my mentor who ingrained in me the lessons Charles Eriksen expressed in DWLA. Gordon Logan and Joseph Lappin, along with two anonymous reviewers, provided helpful comments on the essay. Support for this writing project was provided by the Centennial Research Fund, Vanderbilt University.

\section{References}

Adams, J. K. (1957). Laboratory studies of behavior without awareness. Psychological Bulletin, 54(5), 383.

Alais, D. (2012) Binocular rivalry: Competition and inhibition in visual perception. WIREs Cognitive Science, 3, 87-103. doi: https://doi. org $/ 10.1002 /$ wcs. 151

Alais, D. \& Blake, R. (2015) Binocular rivalry and perceptual ambiguity. In Oxford Handbook of Perceptual Organization, J. Wagemans (Ed.), Oxford University Press.

Al-Hazen, I. (1024/1989). The Optics of Ibn Al-Haytham: On direct vision, Books I-III, ed. AI Sabra (trans: Sabra, A. I.). London: Warburg Inst.

Allport, F. H. (1955) Theories of perception and the concept of structure. New York: Wiley.

Baker, D. H. (2017). Decoding eye-of-origin outside of awareness. Neuroimage, 147, 89-96.

Barbur, John L., John DG Watson, Richard SJ Frackowiak, and Semir Zeki (1993) Conscious visual perception without V1. Brain 116, no. 6, 1293-1302.

Binda, P., Pereverzeva, M., \& Murray, S. O. (2013). Attention to bright surfaces enhances the pupillary light reflex. Journal of Neuroscience, 33(5), 2199-2204.

Blake, R. (1998) What can be perceived in the absence of visual awareness? Current Directions in Psychological Science. 6, 157-162.

Blake, R. (2014) Binocular rivalry updated. In The new visual neurosciences, J.S. Werner \& L.M. Chalupa (Eds), MIT Press. 827-846.

Blake, R., \& Cormack, R. H. (1979). Psychophysical evidence for a monocular visual cortex in stereoblind humans. Science, 203(4377), 274-275.

Blake, R. \& Fox, R. (1974) Adaptation to invisible gratings and the site of binocular rivalry suppression. Nature, 249, 488-490.

Blake, R., Goodman, R., Tomarken, A.T. \& Kim, H.Y. (2019) Individual differences in continuous flash suppression: Potency and linkages to binocular rivalry dynamic. Vision Research, 160, 10-23. https://doi. org/10.1016/j.visres.2019.04.003

Blake, R. \& Logothetis, N. (2002) Visual competition. Nature Reviews Neuroscience, 3, 13-23. PMID:11823801

Blake, R., Tadin, D., Sobel, K., Chong, S.C. \& Raissian, R. (2006) Strength of early visual adaptation depends on visual awareness. Proceedings of the National Academy of Sciences, USA. 103, 4783-4788. PMID: 15147493
Blakemore, C., \& Sutton, P. (1969). Size adaptation: A new aftereffect. Science, 166(3902), 245-247.

Block, N. (1995) On a confusion about a function of consciousness. Behavioral and Brain Sciences, 18, 227-287.

Boyer, J. L., Harrison, S., \& Ro, T. (2005). Unconscious processing of orientation and color without primary visual cortex. Proceedings of the National Academy of Sciences, 102(46), 16875-16879.

Brascamp, J., Sterzer, P., Blake, R. \& Knapen, T. (2018) Multistable perception, and the role of frontoparietal cortex in perceptual inference, Annual Review of Psychology, 69, 77-103. https://doi.org/10. 1146/annurev-psych-010417-085944

Breitmeyer, B. G. (2014). Contributions of magno-and parvocellular channels to conscious and non-conscious vision. Philosophical Transactions of the Royal Society B: Biological Sciences, 369(1641), 20130213.

Breitmeyer, B. G., Koç, A., Öğmen, H., \& Ziegler, R. (2008). Functional hierarchies of nonconscious visual processing. Vision research, 48(14), 1509-1513.

Carlson, T.A. \& He, S. (2000). Visible binocular beats from invisible monocular stimuli during binocular rivalry. Current Biology, 10(17), 1055-1058.

Cave, C., Blake, R. \& McNamara (1998) Binocular rivalry disrupts visual priming. Psychological Science, 9, 299-302.

Cha, O., Son, G., Chong, S. C., Tovar, D. A., \& Blake, R. (2019). Novel procedure for generating continuous flash suppression: Seurat meets Mondrian. Journal of vision, 19(14), 1. https://doi.org/10.1167/19.14.1

Chalmers, D. J. (1996). The conscious mind: In search of a fundamental theory. Oxford University Press.

Christensen, M. S., Kristiansen, L., Rowe, J. B., \& Nielsen, J. B. (2008). Action-blindsight in healthy subjects after transcranial magnetic stimulation. Proceedings of the National Academy of Sciences, 105(4), 1353-1357.

Chun, M. M., \& Jiang, Y. (1998). Contextual cueing: Implicit learning and memory of visual context guides spatial attention. Cognitive psychology, 36(1), 28-71.

Cowey, A., \& Stoerig, P. (1991). The neurobiology of blindsight. Trends in neurosciences, 14(4), 140-145.

Cowey, A., \& Stoerig, P. (2001). Detection and discrimination of chromatic targets in hemianopic macaque monkeys and humans. European journal of neuroscience, 14(8), 1320-1330.

de Gelder, B., Vroomen, J., Pourtois, G., \& Weiskrantz, L. (1999). Nonconscious recognition of affect in the absence of striate cortex. Neuroreport, 10(18), 3759-3763.

de Haan, E. H., \& Cowey, A. (2011). On the usefulness of 'what'and 'where'pathways in vision. Trends in Cognitive Sciences, 15(10), 460-466.

Di Luca, M., Ernst, M. O., \& Backus, B. T. (2010). Learning to use an invisible visual signal for perception. Current Biology, 20(20), 1860-1863.

Diederen, K. M. J., Van Lutterveld, R., \& Sommer, I. (2012). Neuroimaging of voice hearing in non-psychotic individuals: a mini review. Frontiers in Human Neuroscience, 6, 111.

Dienes, Z., \& Seth, A. (2010). Gambling on the unconscious: A comparison of wagering and confidence ratings as measures of awareness in an artificial grammar task. Consciousness and Cognition, 19(2), 674-681.

Dixon, N. F. (1958). The effect of subliminal stimulation upon autonomic and verbal behavior. The Journal of Abnormal and Social Psychology, 57(1), 29.

Dixon N.F. McGraw-Hill; London, UK: 1971. Subliminal perception: the nature of a controversy.

Drew, T., Vo, M.L.-H., \& Wolfe, J.M. (2013). The invisible gorilla strikes again: Sustained inattentional blindness in expert witnesses. Psychological Science, 24(9), 1848-1853. 
Dubois, J., \& Faivre, N. (2014). Invisible, but how? The depth of unconscious processing as inferred from different suppression techniques. Frontiers in psychology, 5, 1117.

Dux, P. E., \& Marois, R. (2009). The attentional blink: A review of data and theory. Attention, Perception, \& Psychophysics, 71(8), 1683-1700.

Erdelyi, M.H. (1974) A new look at the new look: perceptual defense and vigilance. Psychological Review, 81, 1-25.

Eriksen, C. W. (1951). Perceptual defense as a function of unacceptable needs. The Journal of Abnormal and Social Psychology, 46(4), 557.

Eriksen, C. W. (1956). Subception: Fact or artifact?. Psychological Review, 63(1), 74.

Eriksen, C.W. (1960) Discrimination and learning without awareness. Psychological Review, 67, 279-300.

Fang, F., \& He, S. (2005). Cortical responses to invisible objects in the human dorsal and ventral pathways. Nature Neuroscience, 8(10), 1380-1385. https://doi.org/10.1038/nn1537.

Fiser, J., \& Aslin, R. N. (2001). Unsupervised statistical learning of higher-order spatial structures from visual scenes. Psychological science, 12(6), 499-504.

Fuhrer, M. J., \& Eriksen, C. W. (1960). The unconscious perception of the meaning of verbal stimuli. The Journal of Abnormal and Social Psychology, 61(3), 432.

Galvin, S. J., Podd, J. V., Drga, V., \& Whitmore, J. (2003). Type 2 tasks in the theory of signal detectability: Discrimination between correct and incorrect decisions. Psychonomic bulletin \& review, 10(4), 843-876.

Garner, W. R., Hake, H. W., \& Eriksen, C. W. (1956) Operationism and the concept of perception. Psychological Review, 1956, 63, 149- 159.

Gayet, S., Van der Stigchel, S., \& Paffen, C. L. (2014). Breaking continuous flash suppression: competing for consciousness on the presemantic battlefield. Frontiers in psychology, 5, 460.

Geisler, W. S. (2008). Visual perception and the statistical properties of natural scenes. Annual Review of Psychology, 59, 167-192.

Gerdes, A. B., \& Alpers, G. W. (2014). You see what you fear: spiders gain preferential access to conscious perception in spider-phobic patients. Journal of Experimental Psychopathology, 5(1), 14-28.

Gibson, J.J., \& Radnor, M. (1937) Adaptation with negative aftereffect. Psychological Review, 44, 222-244.

Goodale, M. A. \& Milner, A.D. (1992). Visual pathways to perception and action. Trends in Neurosciences, 15(1), 20-25.

Gray, K. L. H., Adams, W. J., \& Garner, M. (2010). Preferential processing of fear faces: Emotional content vs. low-level visual properties. Journal of Vision, 10(7):610a, http://www.journalofvision.org/content/10/7/610, doi:https://doi.org/10.1167/10.7.610.

Hedger, N., Gray, K. L., Garner, M., \& Adams, W. J. (2016). Are visual threats prioritized without awareness? A critical review and metaanalysis involving 3 behavioral paradigms and 2696 observers. Psychological bulletin, 142(9), 934.

Holender, D. (1986). Semantic activation without conscious identification in dichotic listening, parafoveal vision, and visual masking: A survey and appraisal. Behavioral and Brain Sciences, 9(1), 1-23.

Hong, S. W., \& Blake, R. (2009). Interocular suppression differentially affects achromatic and chromatic mechanisms. Attention, Perception, \& Psychophysics, 71(2), 403-411.

Hubbard, E. M., Arman, A. C., Ramachandran, V. S., \& Boynton, G. M. (2005). Individual differences among grapheme-color synesthetes: brain-behavior correlations. Neuron, 45(6), 975-985.

Jagiello, R., Pomper, U., Yoneya, M., Zhao, S., \& Chait, M. (2019). Rapid Brain Responses to familiar vs. Unfamiliar Music-an eeG and pupillometry study. Scientific reports, 9(1), 1-13.

Jiang, Y., Costello, P., Fang, F., Huang, M., \& He, S. (2006). A genderand sexual orientation-dependent spatial attentional effect of invisible images. Proceedings of the National Academy of Sciences, 103(45), 17048-17052.

Kaufman, L., \& Kaufman, J. H. (2000). Explaining the moon illusion. Proceedings of the National Academy of Sciences, 97(1), 500-505.
Kihlstrom, J. F. (1987). The cognitive unconscious. Science, 237(4821), $1445-1452$.

Kihlstrom, J.F. (1996). Perception without awareness of what is perceived, learning without awareness of what is learned. In M. Velmans (Ed.), The science of consciousness: Psychological, neuropsychological, and clinical reviews (pp. 23-46). London: Routledge.

Kim, C.Y. \& Blake, R. (2005) Psychophysical magic: rendering the visible "invisible", Trends in Cognitive Sciences, 9, 381-388. PMID: 16006172

Kim, C.Y. and Blake, R. (2013) Revisiting the perceptual reality of synesthetic color. In Oxford Handbook of Synesthesia J. Simner and E. Hubbard (Eds), Oxford University Press, pp. 283-316.

Kim, H-Y., Kim, C-Y. \& Blake, R. (2017) Monocular perceptual deprivation from interocular suppression temporarily Imbalances ocular dominance, Current Biology, 27, 884-889.

Knill, D. C., \& Pouget, A. (2004). The Bayesian brain: the role of uncertainty in neural coding and computation. TRENDS in Neurosciences, 27(12), 712-719.

Koch, C. (2004) The quest for consciousness: A neurobiological approach. Robertson \& Co. Denver CO.

Koenderink, J.J. (2012). Visual awareness. Utrecht, The Netherlands: De Clootcrans Press. (An E-book available at http://www. gestaltrevision.be/pdfs/koenderink/Awareness.pdf.)

Kolb, F. C., \& Braun, J. (1995). Blindsight in normal observers. Nature, 377(6547), 336-338.

Kouider, S., \& Dehaene, S. (2007). Levels of processing during nonconscious perception: a critical review of visual masking. Philosophical Transactions of the Royal Society B: Biological Sciences, 362(1481), 857-875.

Kramer, A., Coles, M., Eriksen, B., Garner, W., Hoffman, J., \& Lappin, J. (1994). Charles Eriksen Past, present, and future. Perception \&Psychophysics, 55(1), 1-8.

Kravitz, D. J., Saleem, K. S., Baker, C. I., \& Mishkin, M. (2011). A new neural framework for visuospatial processing. Nature Reviews Neuroscience, 12(4), 217-230.

Laeng, B., \& Sulutvedt, U. (2014). The eye pupil adjusts to imaginary light. Psychological science, 25(1), 188-197.

Lappin, J.S., Morse, D. \& Seiffert, A.E. (2016). The channel capacity of visual awareness divided among multiple moving objects. Attention, Perception, \& Psychophysics, 78, 2469-2493. DOI https://doi.org/ 10.3758/s13414-016-1162-z

Lappin, J.S., Seiffert, A.E., \& Bell, H.H. (2020). The limited capacity of visual perception: Spreading attention divides the rates of perceptual processes. Attention, Perception, \& Psychophysics, 92. https://doi. org/10.3758/s13414-020-01973-9

Lau, H. C., \& Passingham, R. E. (2006). Relative blindsight in normal observers and the neural correlate of visual consciousness. Proceedings of the National Academy of Sciences, 103(49), 18763-18768.

Lazarus, R. S., \& McCleary, R. A. (1951) Autonoraic discrimination without awareness: A study of subception. Psychological Review, $58,113-122$.

LeDoux, J. E., Michel, M., \& Lau, H. (2020). A little history goes a long way toward understanding why we study consciousness the way we do today. Proceedings of the National Academy of Sciences, 117(13), 6976-6984.

Levi, D.M. (2008). Crowding - an essential bottleneck for object recognition: a mini-review. Vision Res. 48, 635-654.

Lin, Z., \& He, S. (2009). Seeing the invisible: the scope and limits of unconscious processing in binocular rivalry. Progress in neurobiology, 87(4), 195-211.

Ludwig, K., Kathmann, N., Sterzer, P., \& Hesselmann, G. (2015). Investigating category-and shape-selective neural processing in ventral and dorsal visual stream under interocular suppression. Human Brain Mapping, 36(1), 137-149. 
Madipakkam, A. R., Rothkirch, M., Dziobek, I., \& Sterzer, P. (2017). Unconscious avoidance of eye contact in autism spectrum disorder. Scientific Reports, 7(1), 1-6.

Meng, M., \& Tong, F. (2004). Can attention selectively bias bistable perception? Differences between binocular rivalry and ambiguous figures. Journal of vision, 4(7), 2-2.

Merikle P. M., Daneman M. (1998) Psychological investigations of unconscious perception. Journal of Consciousness Studies, 5:5-18.

Mishkin, M., Ungerleider, L. G., \& Macko, K. A. (1983). Object vision and spatial vision: two cortical pathways. Trends in neurosciences, 6, 414-417.

Moors, P., Hesselmann, G., Wagemans, J., van Ee (2017) Continuous flash suppression: stimulus fractionation rather than integration. Trends in Cognitive Sciences, 21(10), 719-721.

Morgan, M. J., Mason, A. J. S., \& Solomon, J. A. (1997). Blindsight in normal subjects. Nature, 385(6615), 401-402.

Naber, M., \& Nakayama, K. (2013). Pupil responses to high-level image content. Journal of vision, 13(6), 7-7.

Newhall, S. M. \& Sears, R. R. (1933) Conditioning finger retraction to visual stim near the absolute threshold. Comparative Psychology Monographs, 9(43).

Norman, J. F., Lappin, J. S., \& Zucker, S. W. (1991). The discriminability of smooth stereoscopic surfaces. Perception, 20(6), 789-807.

Overgaard, M., Timmermans, B., Sandberg, K., \& Cleeremans, A. (2010). Optimizing subjective measures of consciousness. Consciousness and Cognition, 19(2), 682-684.

Pearson, J., \& Kosslyn, S. M. (2015). The heterogeneity of mental representation: ending the imagery debate. Proceedings of the National Academy of Sciences, 112(33), 10089-10092.

Prioli, S.C., Kahan, T.A. (2015) Identifying words that emerge into consciousness: effects of word valence and unconscious previewing. Consciousness and Cognition, 35, 88-97.

Purves, D., \& Lotto, R.B. (2000). An empirical explanation of color contrast. Proceedings of the National Academy of Sciences, 97(23), 12834-12839.

Purves, D., \& Lotto, R. B. (2003). Why we see what we do: An empirical theory of vision. Sinauer Associates.

Ramsøy, T. Z., \& Overgaard, M. (2004). Introspection and subliminal perception. Phenomenology and the Cognitive Sciences, 3, 1-23.

Ress, D., \& Heeger, D. J. (2003). Neuronal correlates of perception in early visual cortex. Nature neuroscience, 6(4), 414-420.

Robichaud, L., \& Stelmach, L. B. (2003). Inducing blindsight in normal observers. Psychonomic bulletin \& review, 10(1), 206-209.

Schall, J.D., Nawrot, M., Blake, R. \& Yu, K. (1993) Visually guided attention is neutralized when informative cues are visible but unperceived. Vision Research. 33, 2057-2064.

Schwiedrzik, C. M., \& Sudmann, S. S. (2020). Pupil diameter tracks statistical structure in the environment to increase visual sensitivity. Journal of Neuroscience.

Sekuler, R., Sekuler, A. B., \& Lau, R. (1997). Sound changes perception of visual motion. Nature, 384, 308-309.

Seymour, K., Rhodes, G., Stein, T., \& Langdon, R. (2016). Intact unconscious processing of eye contact in schizophrenia. Schizophrenia Research: Cognition, 3, 15-19.

Sheth, B. R., \& Pham, T. (2008). How emotional arousal and valence influence access to awareness. Vision research, 48(23-24), 2415-2424.

Shimojo, S., \& Nakayama, K. (1990). Real world occlusion constraints and binocular rivalry. Vision research, 30(1), 69-80.

Silvanto, J., \& Rees, G. (2011). What does neural plasticity tell us about role of primary visual cortex (V1) in visual awareness?. Frontiers in psychology, 2, 6 .

Simons, D.J. \& Chabris, C.F, (1999). Gorillas in our midst: sustained inattentional blindness for dynamic events. Perception, 28, 1059-1074.

Sklar, A.Y., Levy, N., Goldstein, A., Mandel, R., Maril, A. \& Hassin, R.R. (2012) Reading and doing arithmetic nonconsciously. Proceedings of the National Academy of Sciences USA, 109(48), 19614-19619.
Sobel, K. \& Blake, R. (2003) Subjective contours and binocular rivalry. Vision Research, 43, 1533-1540.

Soto, D., Mäntylä, T. \& Silvanto, J. (2011) Working memory without consciousness. Current Biology 21, R912-R913.

Sterzer, P., Kleinschmidt, A., \& Rees, G. (2009). The neural bases of multistable perception. Trends in Cognitive Sciences, 13(7), 310-318.

Sterzer, P., Stein, T., Ludwig, K., Rothkirch, M., \& Hesselmann, G. (2014). Neural processing of visual information under interocular suppression: a critical review. Frontiers in psychology, 5, 453.

Stoerig, P., Zontanou, A., \& Cowey, A. (2002). Aware or unaware: assessment of cortical blindness in four men and a monkey. Cerebral Cortex, 12(6), 565-574

Tamietto, M., \& De Gelder, B. (2010). Neural bases of the non-conscious perception of emotional signals. Nature Reviews Neuroscience, 11(10), 697-709.

Tettamanti, M., Conca, F., Falini, A., \& Perani, D. (2017). Unaware processing of tools in the neural system for object-directed action representation. Journal of Neuroscience, 37(44), 10712-10724.

Thompson, P. (1980). Margaret Thatcher: a new illusion. Perception, 9(4), 483.

Tong, F. (2003). Primary visual cortex and visual awareness. Nature Reviews Neuroscience, 4(3), 219-229.

Tong, F., Nakayama, K., Vaughan, J.T. and Kanwisher, N., 1998. Binocular rivalry and visual awareness in human extrastriate cortex. Neuron, 21(4), 753-759.

Tsuchiya, N., \& Koch, C.(2004). Continuous flash suppression [Abstract]. Journal of Vision, 4: 61a, http://journalofvision.org/4/8/ 61/, doi:https://doi.org/10.1167/4.8.61.

Tsuchiya, N., \& Koch, C. (2005). Continuous flash suppression reduces negative afterimages. Nature Neuroscience, 8(8), 1096-1101.

Vieira, J. B. Wen, S., Oliver, L.D., Mitchell, D.G.V. (2017) Enhanced conscious processing and blindsight-like detection of fearconditioned stimuli under continuous flash suppression. Experimental Brain Research, 235, 3333-3344.

von Helmholtz H. 1867. Handbuch Der Physiologischen Optik. Leipzig: Leopold Voss.

Ward, J. (2013). Synesthesia. Annual review of psychology, 64, 49-75.

Weiskrantz, L. (1980). Varieties of residual experience. The Quarterly journal of experimental psychology, 32(3), 365-386.

Weiskrantz, L., Warrington, E., Sanders, M.D. \& Marshall, J. (1974) Visual capacity in the hemianopic field following a restricted occipital ablation. Brain, 97, 709-728.

Whalen, P. J., Kagan, J., Cook, R. G., Davis, F. C., Kim, H., Polis, S., ... Johnstone, T. (2004). Human amygdala responsivity to masked fearful eye whites. Science, 306(5704), 2061-2061.

Wilcott, R. C. (1953) A search for subthreshold conditioning at four different auditory frequencies. Journal of Experimental Psychology, 46, 271-277.

Wohlgemuth, A. (1911). On the after-effect of seen movement. British Journal of Psychology Monograph Supplement, 1-117.

Yang, E., Brascamp, J., Kang, M.S. \& Blake, R. (2014) On the use of continuous flash suppression for the study of visual processing outside of awareness. Frontiers in Psychology, doi: https://doi.org/10. 3389/fpsyg.2014.00724

Yang, E., Zald, D. H., \& Blake, R. (2007). Fearful expressions gain preferential access to awareness during continuous flash suppression. Emotion, 7, 882-886. https://doi.org/10.1037/1528-3542.7.4.882

Zadbood, A., Lee, S. H., \& Blake, R. (2011). Stimulus fractionation by interocular suppression. Frontiers in Human Neuroscience, 5, 135.

Zeki, S. and Ffytche, D. H. (1998). The Riddoch syndrome: Insights into the neurobiology of conscious vision. Brain, 121: 25-45.

Publisher's note Springer Nature remains neutral with regard to jurisdictional claims in published maps and institutional affiliations. 